Thorax (1946), 1. 211.

\title{
EXTRAPLEURAL PNEUMOTHORAX IN THE TREATMENT OF PULMONARY TUBERCULOSIS
}

BY

HUGH REID

Liverpool

Surgical treatment of pulmonary tuberculosis centres round the problem of collapse (or relaxation) therapy. This paper is an attempt to assess the value of extrapleural pneumothorax as one of the methods of collapse therapy, either alone or in conjunction with other procedures. There is a difference of opinion about the use of terms to describe this procedure. Pneumonolysis means a loosening of the lung away from the chest, but does not imply iow the loosening or separation should be maintained. Pneumolysis, from its etymology, means a loosening of air and not of the lung, and is, therefore, a misnomer and its use should be discontinued, although it is the term most commonly used by English writers. Apicolysis is included in the term pneumonolysis, but is specific in stating the site of loosening.

Throughout the literature various ways of preventing the lung from re-expanding after pneumonolysis are described, such as filling the resultant space with gauze, fat, oil, muscle, wax (plombierung or plombage), and air (extrapleural pneumothorax). It is with the latter that this paper is chiefly concerned.

The idea of extrapleural pneumothorax is by no means new. Tuffier, in 1891, described and practised "pleuroparietal stripping, that is to say, separation between the parietal pleura and the thoracic cage." In 1910 Tuffier was the first to use human fat to fill the resultant space after performing a pneumonolysis for tuberculosis, and in 1913 he was the first to use air as a filling. He did not, however, insufflate the air until four days after the operation, and the result was a failure.

Schlange (1907) performed an extrapleural pneumonolysis and used iodoform gauze as a temporary filling, in a case of haemoptysis from a tuberculous cavity. Only a very limited mobilization of the apex was done, but it served the immediate necessity and when the cavity had been relaxed the haemoptysis stopped.

Gustav Baer (1913) reported two successful cases of extrapleural pneumonolysis, in which he filled the resultant space with sterilized paraffin wax mixed with bismuth carbonate (plombierung). He described his technique of removal of $4 \mathrm{c.cm}$. of the third or fourth rib from the front, incising the intercostal muscle 
and finding the right plane of cleavage in the endothoracic fascia. His first patient was a man of 38 years who had had a haemoptysis due to pulmonary tuberculosis. There was cavitation in the apex of the left lung and a lesser lesion in the right. As a complication the patient also had albuminuria with casts. Six weeks after the operation the patient died of tuberculous meningitis. At the autopsy the plombe was found to be sterile and surrounded by a whitely gleaming fibrous capsule. The walls of the cavities in the lung had become approximated.

Baer's second patient was a man of 36 years, who had had three severe haemoptyses due to pulmonary tuberculosis in the past five years, and pyrexia for three years. He also had amyloid disease of the kidneys. He had extensive cavitation in the right lung and a small lesion in the left. After the operation he coughed up a little blood-stained sputum and had a slight reactionary temperature, but in a few days the sputum diminished from $130 \mathrm{ml}$. to $15 \mathrm{ml}$. daily, and there was no pyrexia. The albuminuria also improved.

Baer was much encouraged by these results, and concluded that the danger of aspiration into the same or the opposite lung is small, that there is effortless expectoration immediately after the operation, that the cosmetic effect is good, and that the operation is technically simple if skilfully carried out.

Archibald, in 1917, performed a classical operation in which he first did a partial lower thoracoplasty. Two years later he performed an extrapleural apicolysis and filled the space with a muscle graft from the pectoralis major. This was an early attempt to apply the principle of relaxation therapy by apicolysis, combined with maintenance of the space by a muscle graft assisted by thoracoplasty ; but it failed because there was no real separation of the apex.

Sebrechts of Bruges (1929) reported to the thirty-eighth French Congress of Surgery that, after having performed apicolysis, he used as plombage material the two pectoral muscles with their vascular pedicles preserved.

Morriston Davies (1933) used fat grafts, muscle grafts, and paraffin plombe as well as extrapleural pneumothorax, and has done great pioneer work in England. He has discarded all these procedures because in his view the results were so poor.

Nissen (1933) successfully repeated Tuffier's original attempts to use air as a filling after pneumonolysis (extrapleural pneumothorax), but with growing experience he pronounced against its extended use in the treatment of tuberculosis.

In England and America the impetus to give extrapleural pneumothorax an extended trial was initiated by Graf and Schmidt. Graf of Dresden (1936) published a paper on "subfascial pneumonolysis.". His experiences and those of Schmidt of Heidelberg have completely changed the outlook and the scope of this operation. But their experiences refer to early work, and no statistics are available of their late results. Graf recognized that the stripping down of the lung must be carried out much more extensively than was originally considered necessary. He considered surgical emphysema the most important complication, and 
prevented it by introducing a rubber catheter into the extrapleural space and keeping it there for the first few days. Sooner or later he transformed the extrapleural pneumothorax into an oleothorax, with a view to subsequent thoracoplasty. He thinks we shall achieve an effective and non-injurious upper zone thoracoplasty only when we have learned to control the tuberculosis before doing the thoracoplasty. He did not consider his experience with 34 cases over a period of two years sufficiently mature to report statistically.

Schmidt, by January 1938, had performed pneumonolysis 200 times, although only 43 cases were maintained by air ; the others were maintained by different kinds of oil. He found that liquid paraffin was the most useful medium because it was less irritating and was easier to use for outpatients than was air. The primary mortality was $12.5 \%$. His indications were not always definite, because he was sometimes persuaded to do the operation by the patients or their doctors as a last hope. Unfortunately Schmidt has died since the publication of this paper, and it is unlikely that we shall ever know the end-results of this large series of cases.

In 1938 a number of surgeons, stimulated by the work of Graf and Schmidt, published their experiences and immediate results. English work has been much interrupted by the war, and the reports before the war were unsatisfactory. In spite of this a number of surgeons have continued to do the operation and are getting a clearer idea about its indications and results.

Roberts (1938) was the first to perform extrapleural pneumothorax in London at the Brompton Hospital, early in the year 1937. In the first two cases he followed the method of Graf, using a catheter to drain the space. In both, external sinuses formed, and tuberculous pus was drained. In one, the sinus healed and the man is at work and free from symptoms. In the other, gomenolized oil was injected into the sinus and entered the lung through an unsuspected bronchial fistula. The patient died within twenty-four hours. This technique was abandoned, and Schmidt's method, which completely closes the wound, was adopted. In a personal communication recently, Roberts states that the endresults were not so good as he had expected, and that wherever possible he now avoids the operation.

Sellors (1938) summarized the indications for, and results of, extrapleural pneumothorax as follows:

\section{INDICATIONS}

1.-Character of the disease:

(a) too recent or "soft" for thoracoplasty ;

(b) rapid excavation with obvious need for retraction.

2.-Situation of the disease: presence of recent activity in opposite lung.

3.-Age of patient: In growing children extensive rib resection may be postponed or avoided.

4.-Patients who refuse to entertain the idea of thoracoplasty. 
When an artificial pneumothorax was present, Sellors recommended preliminary thoracoscopy to ensure that the adhesions were not divisible intrapleurally. If the extrapleural pneumothorax operation was performed, several courses were open. Both intra- and extrapleural spaces could be maintained with air refills, or the septum between these spaces could be divided by thoracoscopy and cautery at a later date, or the septum could be divided at the time of operation.

\section{Figures (71 CASES)}

In the absence of artificial pneumothorax

Extrapleural pneumothorax only

In the presence of artificial pneumothorax

Extrapleural pneumothorax only. Septum left intact

Extrapleural and intrapleural pneumothorax spaces combined by later division of septum

Extrapleural pneumonolysis with division of septum at time of operation.
331 death from rupture of cavity. 7 failures: either infection or early re-expansion.

5

92 cases of tuberculous infection of pleura.

241 death from pneumonia in opposite lung 4 cases of pleural infection.

Brock (1938) stated that when an intrapleural pneumothorax is indicated and fails, this is the indication for extrapleural pneumothorax, which has the great advantage that it produces a strictly selective collapse, a feature that is particularly important in dealing with bilateral disease. His mortality in the first 50 cases was $10 \%$. He classified the results as being good in $48 \%$ and very good in $16 \%$, but stresses that these are immediate results judged by the efficacy of the collapse obtained in the diseased lung. So far as the ultimate fate of the extrapleural pneumothorax is concerned, Brock found it impossible to give an answer ; some cases had gone for over a year with no sign of obliteration of the space, while in other cases obliteration had advanced rapidly.

Maurer and de Savitsch (1938) reported 78 cases for statistical study six to eighteen months after the initiation of the procedure. In 6 of these the operation was attempted but had to be abandoned because of very severe peripleuritis. In another case thoracoplasty followed extrapleural pneumothorax, and in yet another, extrapleural pneumothorax successfully supplemented artificial pneumothorax. This leaves 70 cases in which extrapleural pneumothorax was the sole measure of collapse-therapy. Maurer adopted the following classification: (a) collapse perfect, no tubercle bacilli in sputum, no complications ; (b) good collapse, tubercle bacilli persisting in sputum, transient complications ; (c) unsatisfactory collapse and aggravation of symptoms; (d) death. Out of the 70 cases, 47 fulfilled Maurer's ideal indication-namely, that thoracoplasty was undesirable and that the lesions were fairly "young." 
The results were as follows:

TABLE I

\begin{tabular}{|c|c|c|c|c|c|}
\hline \multicolumn{3}{|c|}{ Ideal Cases } & \multicolumn{2}{|c|}{$\begin{array}{c}\text { Cases where thoracoplasty wa } \\
\text { but not desirable }\end{array}$} & \multirow{2}{*}{$\begin{array}{c}\text { possible } \\
39 \% \\
30 \% \\
10 \% \\
21 \%\end{array}$} \\
\hline $\begin{array}{l}\text { A } \\
\mathbf{B} \\
\mathbf{C} \\
\mathbf{D}\end{array}$ & $\begin{array}{r}20 \text { cases } \\
13 \text { cases } \\
7 \text { cases } \\
7 \text { cases }\end{array}$ & $\begin{array}{l}42 \% \\
28 \% \\
15 \% \\
15 \%\end{array}$ & $\begin{array}{l}\text { A } \\
\text { B } \\
\text { C } \\
\text { D }\end{array}$ & $\begin{array}{l}9 \text { cases } \\
7 \text { cases } \\
2 \text { cases } \\
5 \text { cases }\end{array}$ & \\
\hline
\end{tabular}

In America, Coryllos (1938) was the first to follow Graf and Schmidt, and he published his experience with 12 cases. There was no mortality or morbidity from the operation, and the immediate results were satisfactory, but his paper was published too early for any general conclusion to have been reached. He expressed doubt about the possibility of maintaining an extrapleural pneumothorax for a sufficiently long time to allow cavities to heal.

Also from America, Dolley, Jones, and Skillen (1940) carried out a world survey that included the individual opinions of surgeons who had had experience in extrapleural pneumothorax.

The conclusions were as follows:

1.-Intrapleural pneumothorax and limited thoracoplasty are to be preferred when they can be reasonably relied on to produce cavity closure and sputum conversion.

2.-When neither is likely to succeed, extrapleural pneumothorax, provided that in a larger measure operative indications fall within the absolute and broad groups, will be instrumental in obtaining approximately $63 \%$ sputum conversions. This figure represents the mean average for 27 clinics and is based on approximately 2,000 cases.

3.-Comparatively early oil-conversion is advisable.

4. - The end-result will be: (a) permanent oleothorax, or (b) partial lung re-expansion with either a small residual oleothorax or obliterating extrapleural fibrosis, with little likelihood that a thoracoplasty will be required.

In a personal communication Barrett and Maxwell summarize a series of cases they have treated by extrapleural pneumothorax at Milford Sanatorium during the last four years. Extrapleural pneumothorax was done in 38 cases ; 30 of these patients had bilateral disease and all had lesions which had excavated. The series includes 2 patients in whom bilateral extrapleural pneumothoraces were done (both are well), and 5 intra-extrapleural operations. The results are that 1 patient is worse, but none has died ; 4 are " in statu quo," but in 3 of these the sputum is negative ; $33(85 \%)$ are greatly improved-it cannot be said that they are controlled because many of them have bilateral disease and some will need treatment on the other side ; 26 patients are sputum-negative, fit, and well ; 11 developed a tuberculous infection in the extrapleural space, but none are clinically worse on this account, and practically all have benefited greatly from the operation. No patient has had a drainage operation, and none has had a 
thoracoplasty. In 3 the infection was of mixed type, but these secondary invaders have been controlled by penicillin.

In some cases the operation was easy, and in others it was completed only after much dissection of extrapleural adhesions. Barrett and Maxwell think that the results in these two groups show that the latter carry a high risk of postoperative complications. In 31 cases the operation was easy ; of these, $16 \%$ developed a tuberculous infection of the extrapleural space. In 7 cases the operation was difficult, and in $70 \%$ the extrapleural space became infected.

Barrett and Maxwell conclude that in upper lobe cavities size does not seem to have much bearing upon the result; that is, large cavities respond as well as small ones, and the risk of a large cavity rupturing into the extrapleural space does not seem to be important.

In about one in every six of their cases the operation had to be abandoned for one reason or another. None of these patients were any the worse for the experience apart from the fact that time had been lost. (These patients are not included in the figures given above.) There was no case of spread after an operation which could be satisfactorily completed, and there was only one case of postoperative atelectasis. The latter fact is odd when contrasted with the risk of atelectasis in patients of this type after thoracoplasty.

In these cases the indications for extrapleural pneumothorax were: (1) bilateral disease with active cavitation ; (2) young subjects ; (3) patients with small apical lesions in which a selective artificial pneumothorax could not be obtained ; (4) patients with an unstable lesion in the upper lobe.

\section{Personal Experience}

This paper is based upon 54 consecutive cases of extrapleural pneumothorax performed at the North Wales Sanatorium between the years 1938 and 1944. All the patients came from Wales with the exception of two who came from Southport.

Selection of patients for operation.-In all my cases except one, an artificial pneumothorax had been attempted. In most instances it had failed because the visceral and parietal pleurae were so extensively adherent that not even an initial pocket of air could be introduced. In a number of others a pneumothorax had been induced, but adhesions at the apex, which could not be dealt with by intrapleural pneumonolysis, prevented effective relaxation of the diseased lung area.

Phrenicectomy had been performed in twelve cases, but without adequate improvement. Pneumoperitoneum was not used, because this treatment was not made use of until late in 1943.

The advisability of performing a thoracoplasty was discussed in all these cases, but although the main lesion was limited to the apex of one lung, unstable lesions were present in the opposite lung. I felt, therefore, that by performing 
an extrapleural pneumothorax, a considerable area of healthy lung on the more affected side would be saved from obliteration.

The implication of a study of these cases is that where an artificial pneumothorax has failed (either through failure to find a free space or after thoracoscopy with an attempt at division of adhesions), an extrapleural pneumothorax has proved to be a satisfactory surgical way of controlling the lesion itself, leaving as much healthy tissue as possible below the lesion.

The problem of the cavity.-I have observed, by studying a series of cases at the North Wales Sanatorium before thoracoscopy and division of adhesions was practised, that $80 \%$ of patients who have a cavity which is held out by adhesions resulting from an ineffective artificial pneumothorax die within four years.

In almost all the cases reviewed in this paper a cavity of varying extent was present at one or other apex ; below the cavity the lung was healthy, but on the opposite side there was an unstable lesion. The cases may be classified in four groups. In the first group (18 cases) the lesion on the less affected side was minimal but too unstable to permit thoracoplasty. In this group the indications for treatment by extrapleural pneumothorax were relative rather than absolutethat is to say, some surgeons would feel justified in taking the risk of thoracoplasty.

In a second group, of 5 cases, bilateral apical cavities were present. Treatment might have been attempted by performing bilateral apical thoracoplasty, but it was considered that even a unilateral thoracoplasty was too severe a procedure.

In a third group, of 12 cases, an apical cavity was complicated by an extensive lesion on the opposite side. Indications for an extrapleural pneumothorax were absolute in this group ; that is to say, thoracoplasty was contra-indicated, and the only possible way of stopping progress of the disease was by an extrapleural pneumothorax.

In a fourth group, of 2 cases, there had been a cavity in one side, which had healed, the opposite side had excavated, and attempts to control the recent cavity by performing an artificial pneumothorax on this side had proved ineffective. Indications for extrapleural pneumothorax were also absolute in this group.

Absolute indications. - Case 53 is an example of an absolute indication. This man's left lung was extensively collapsed by a tuberculous pyopneumothorax and was almost functionless. He developed a cavity in the right apex. A right artificial pneumothorax was induced, but was ineffective owing to adhesions. A thoracoscope was introduced, and an attempt made to divide the adhesions, without success. Finally an extrapleural pneumothorax was successfully performed on the right side. The cavity disappeared (as shown in the radiographs), and the remaining healthy portion of the right lung was preserved to carry on respiratory functions. A thoracoplasty will be required to deal with the left-sided pyopneumothorax, but in the meantime the pulmonary disease is controlled and there is no sputum. 
Absolute indications were also seen in 17 other cases. In two of them the patients died from spread of the disease to the opposite side. One patient was very toxic and had an ischio-rectal abscess, and although she lived four years she was not benefited. All the other patients in this group did well, and particularly Case 21 , who had a very large cavity in the left apex, and had previously had a cavity in the right apex. After four years his extrapleural pneumothorax is still being maintained, the right apex is stable and he is doing his full work. Case 24 had a cavity system in her right apex and an extensive lesion on the left. Her extrapleural space has obliterated, but she has recently given birth to a healthy baby without harm to her lungs.

Case 35 illustrates how an extrapleural pneumothorax can be absolutely indicated in the first place and may prepare a patient for a thoracoplasty later on. The case is that of a woman with a large apical cavity on the left, and lesions in the contralateral lung. In January 1943, an artificial pneumothorax on the left was attempted and failed. The first radiograph shows her condition in March, just before an extrapleural pneumothorax was done (Fig. 14). The next (Fig. 15) shows her condition in July, after the operation: the cavity is obliterated and the contralateral lesions have cleared. The third radiograph, taken in October of the same year (Fig. 16), shows the extrapleural space still well marked, without effusion, and extending down to the sixth rib posteriorly; but the underlying cavity has begun to reappear. The fourth radiograph, in August of the following year (Fig. 17), shows that an upper thoracoplasty has been satisfactorily performed, the cavity has disappeared completely, and no lesion can be seen in the contralateral lung. Had the thoracoplasty been done in March, it is probable that the lesions in the contralateral lung would have spread.

\section{Illustrative CASE Histories}

CASE 4 (woman, aged 29).- Since 1936 the patient had had frequent colds. In 1937 pain developed in right side of the chest, and by 1938 there was cough and sputum. In October, 1938, stained sputum showed a positive reaction, and on Dec. 16 the patient was admitted to the North Wales Sanatorium, Denbigh (Fig. 1). On Jan. 27, 1939, right artificial pneumothorax was induced (Fig. 2), and on May 25 right extrapleural pneumothorax was performed. A small tear was made in the parietal pleura, causing complete collapse of the lung, and auricular fibrillation. The wound was sewn up and the operation abandoned (Fig. 3). On June 28 thoracoscopy was performed and the artificial pneumothorax and extrapleural pneumothorax were joined. On Aug. 20 satisfactory pneumolysis was carried out, with the establishment of a large extrapleural pneumothorax space (Fig. 4). On Feb. 23, 1940, the patient was discharged. She had a slight cough but no sputum, and the general condition was fair (Fig. 5). The blood sedimentation rate was 18/45. She died soon after leaving the sanatorium.

CASE 21 (man, aged 43).-A patient who for years had been producing slightly stained sputum was admitted to Southport (New Hall) Sanatorium in August, 1938. Sputum was positive and there was lassitude and loss of weight. He had been having gold treatment, but this was abandoned. In June, 1939, left artificial pneumothorax was induced, but was found to be contra-selective. The condition grew worse, and he was sent to the North 

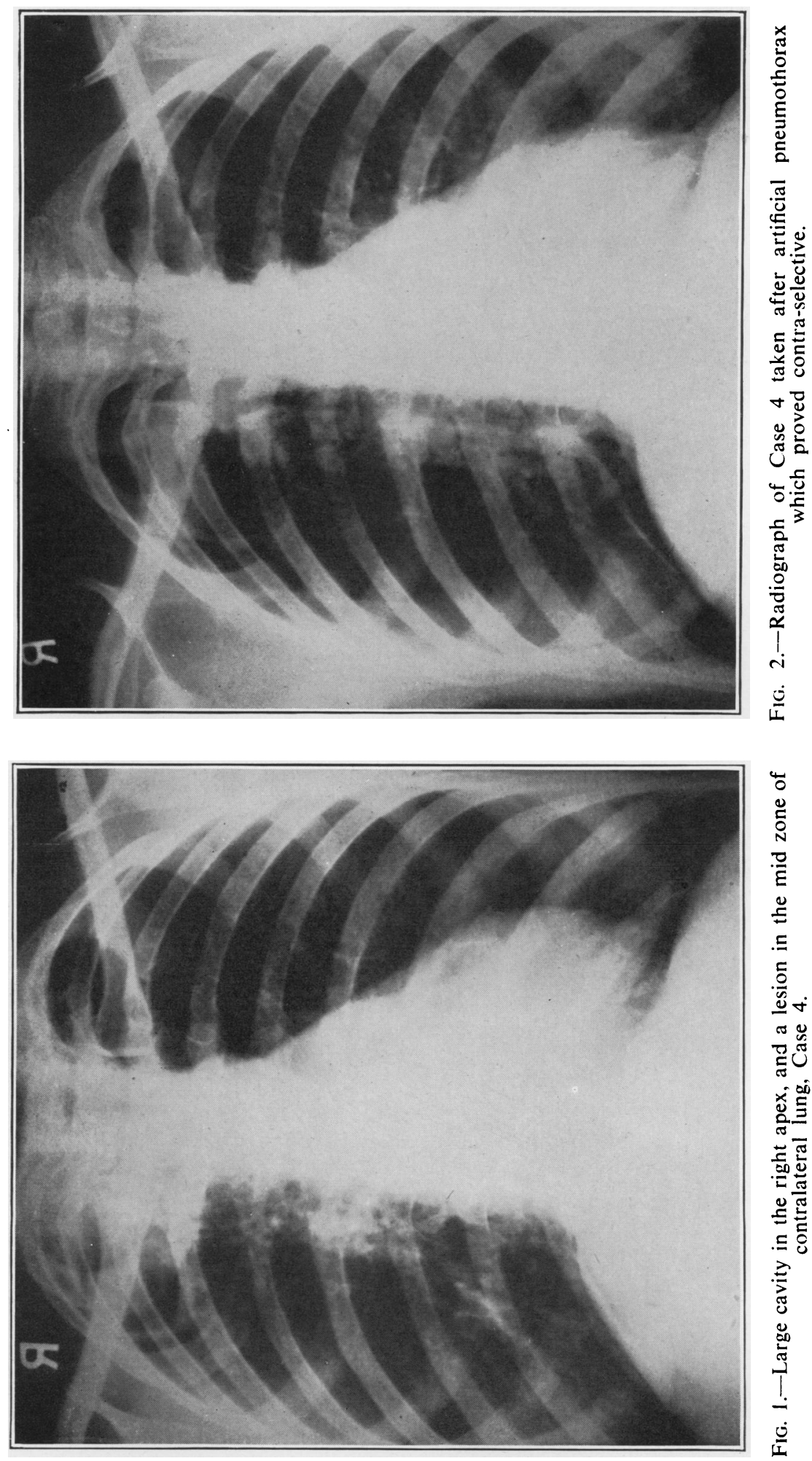

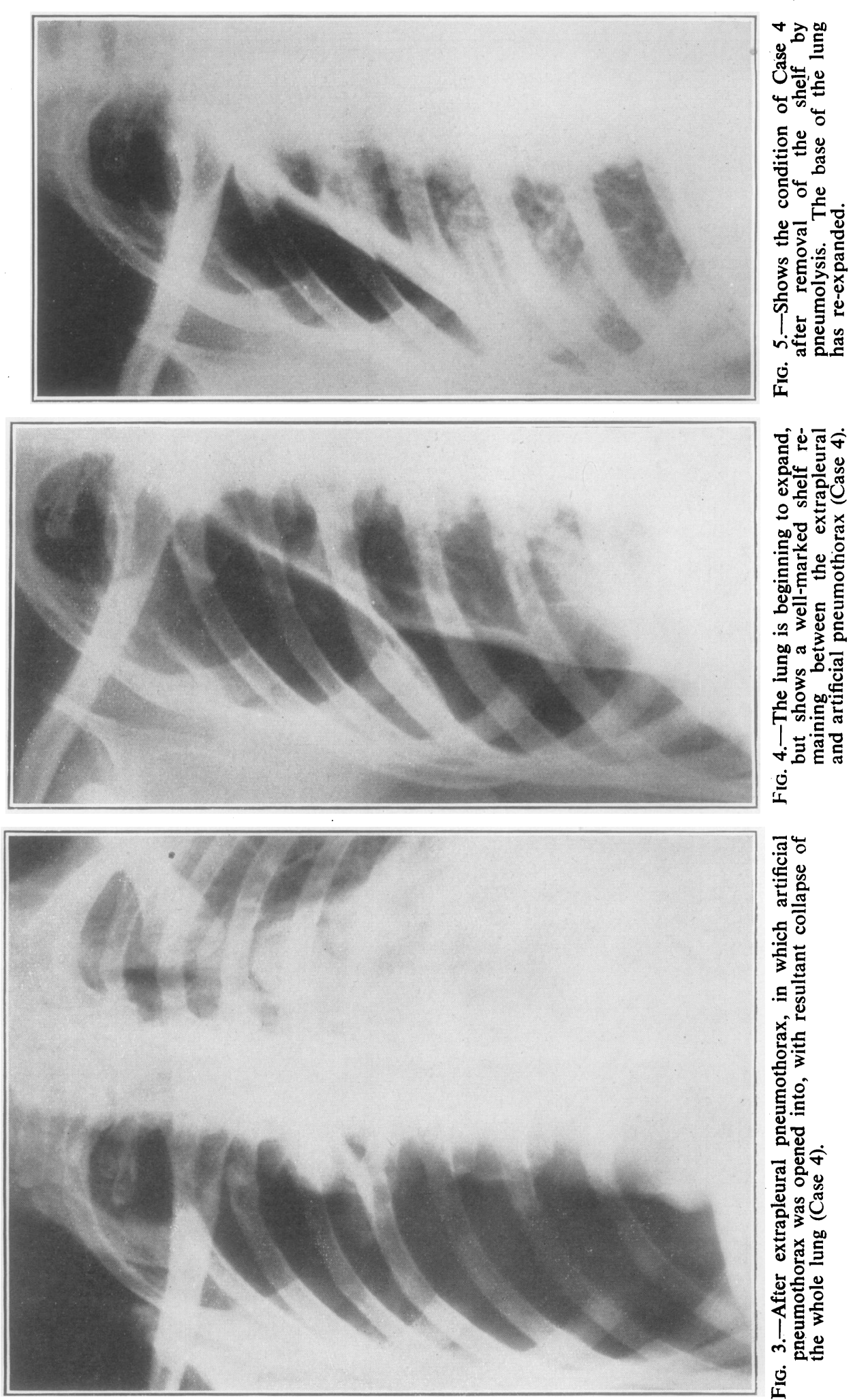

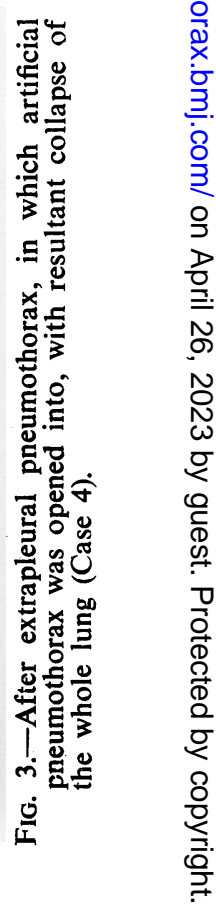



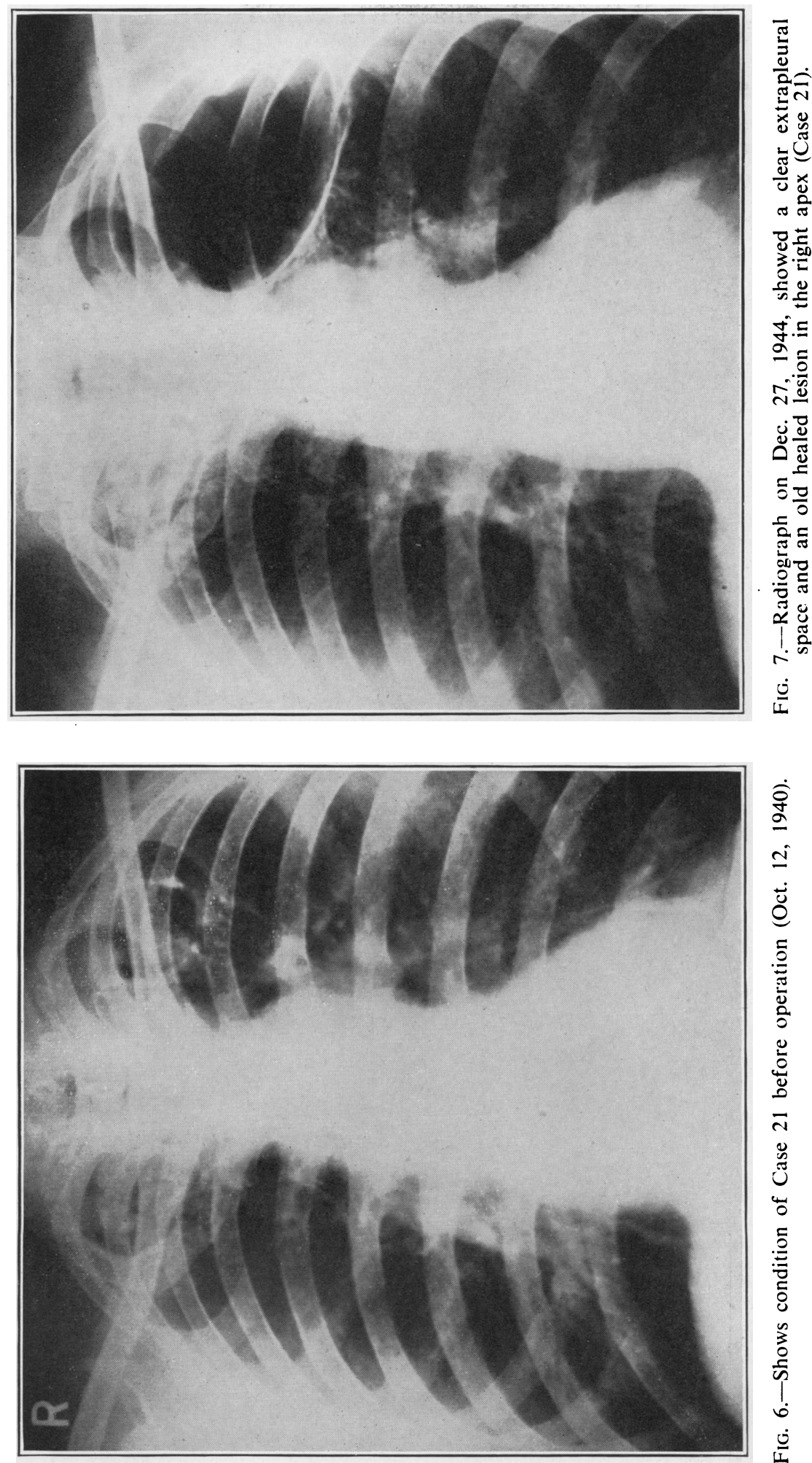

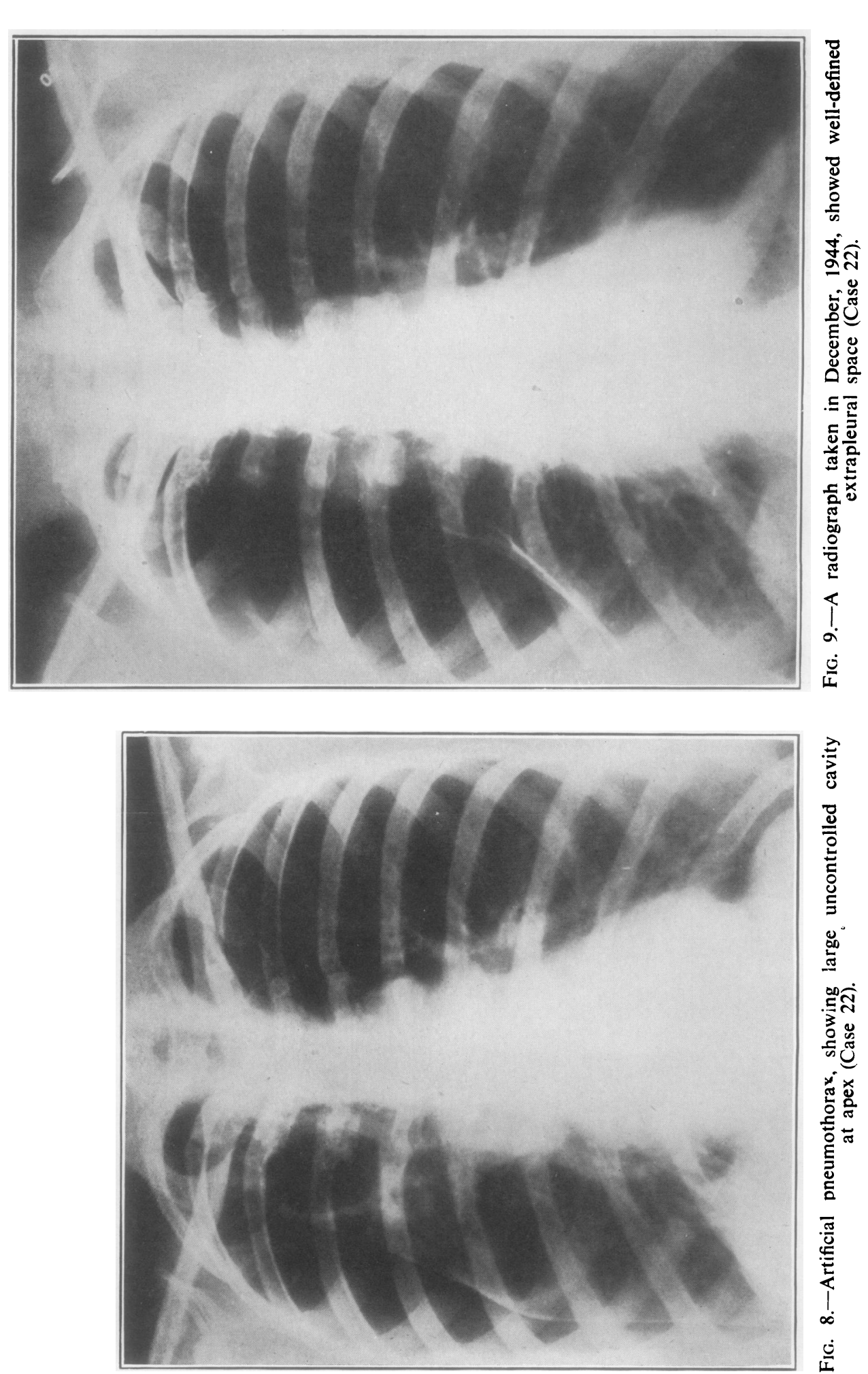

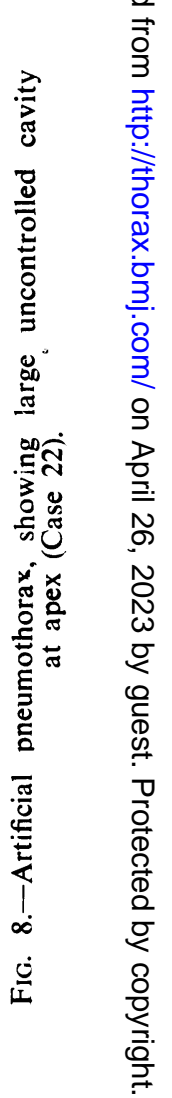



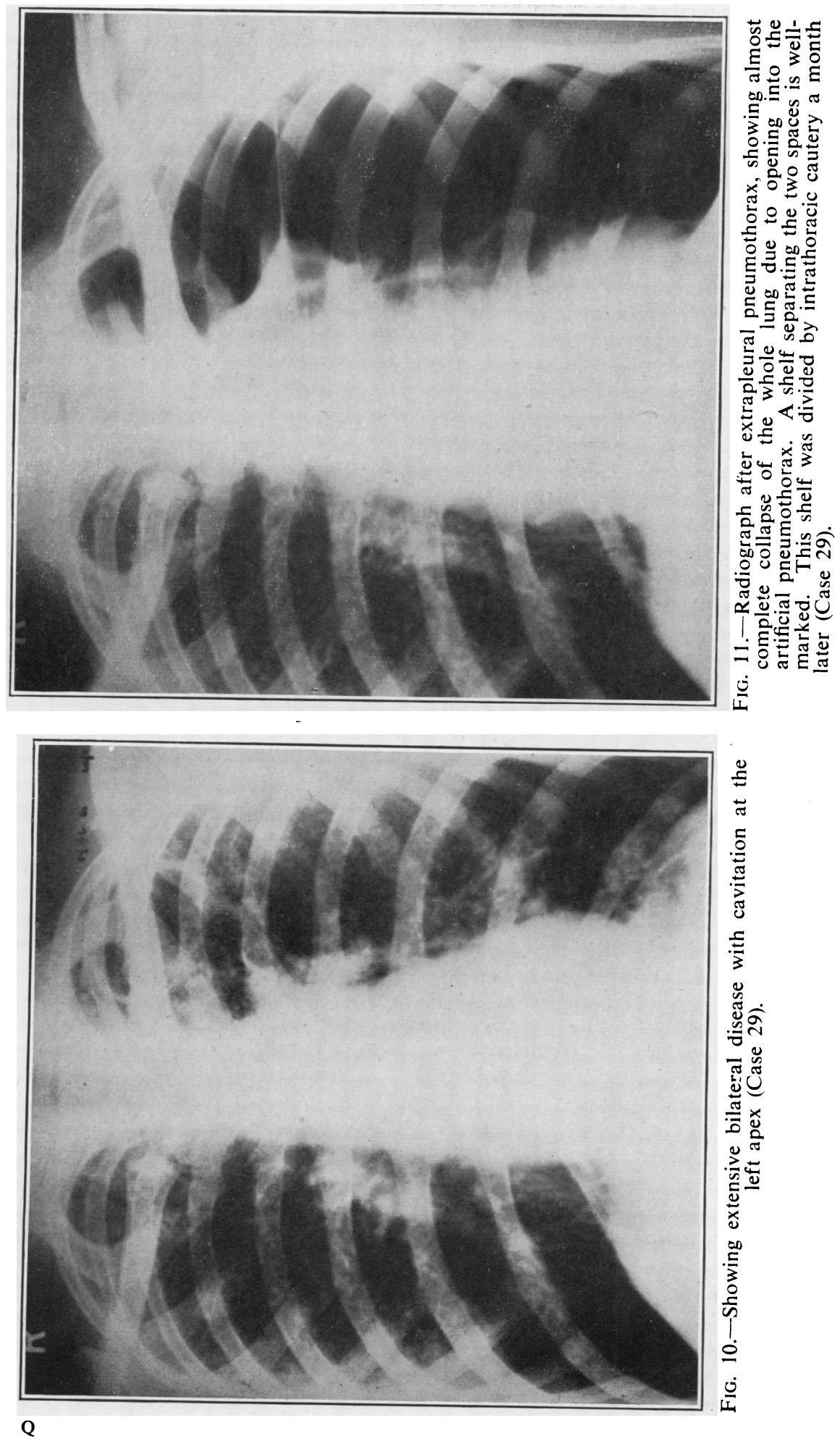

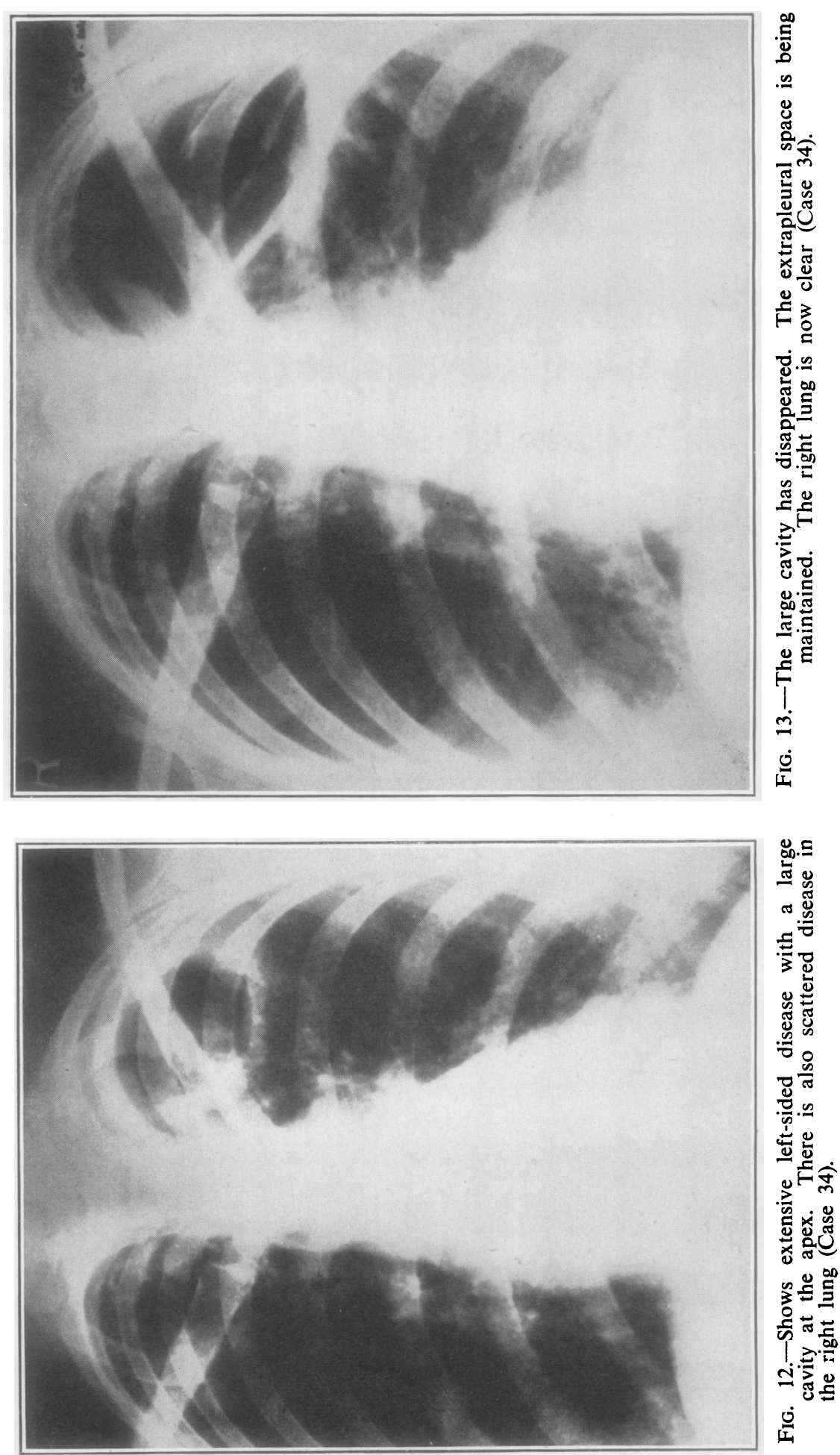


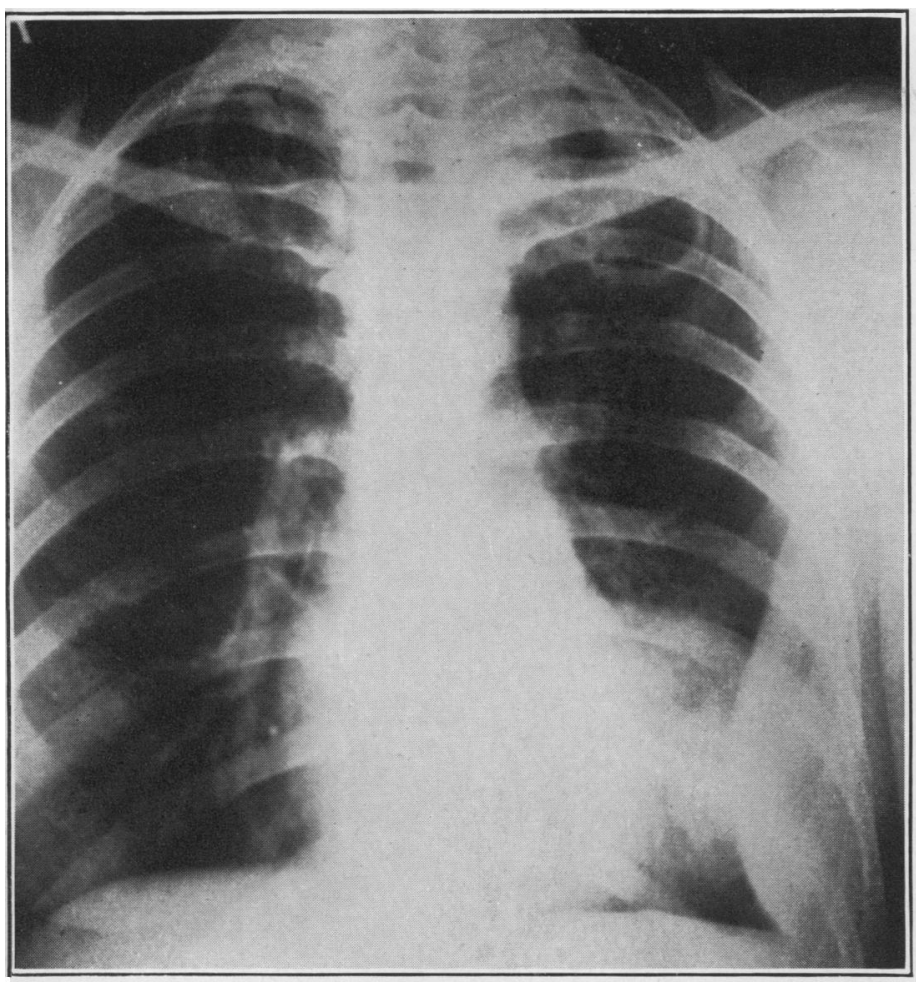

Fig. 14.-Shows cavitation at the left apex and disease in the left lung (Case 35).

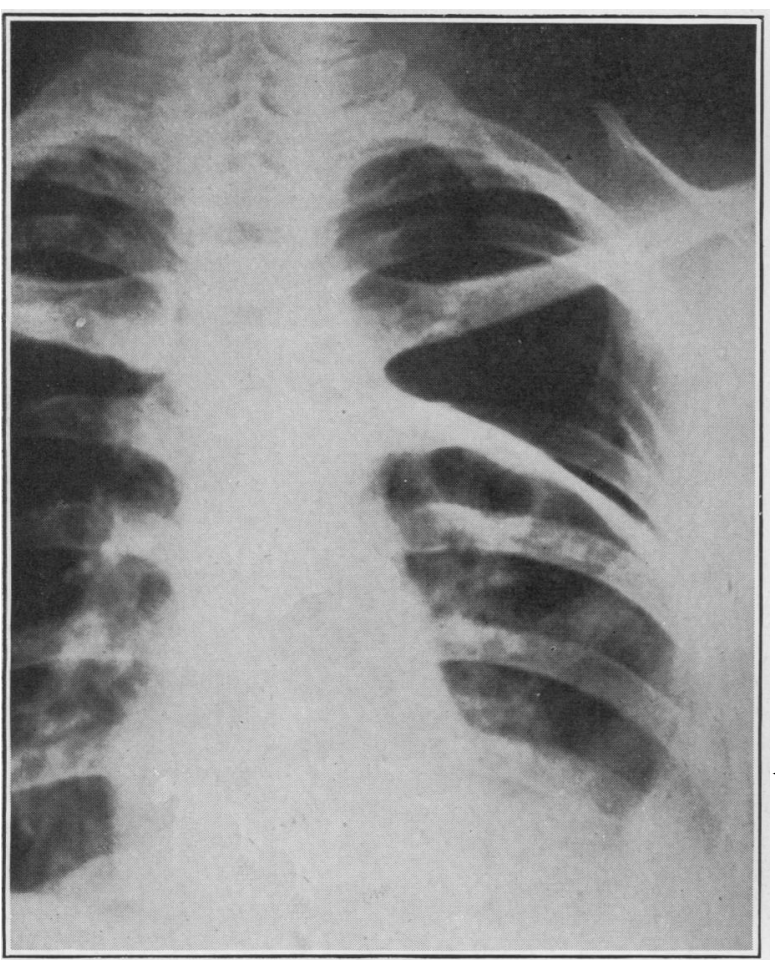

Fig. 16. - The cavity (Case 35) is beginning to reappear in spite of good extrapleural pneumothorax.

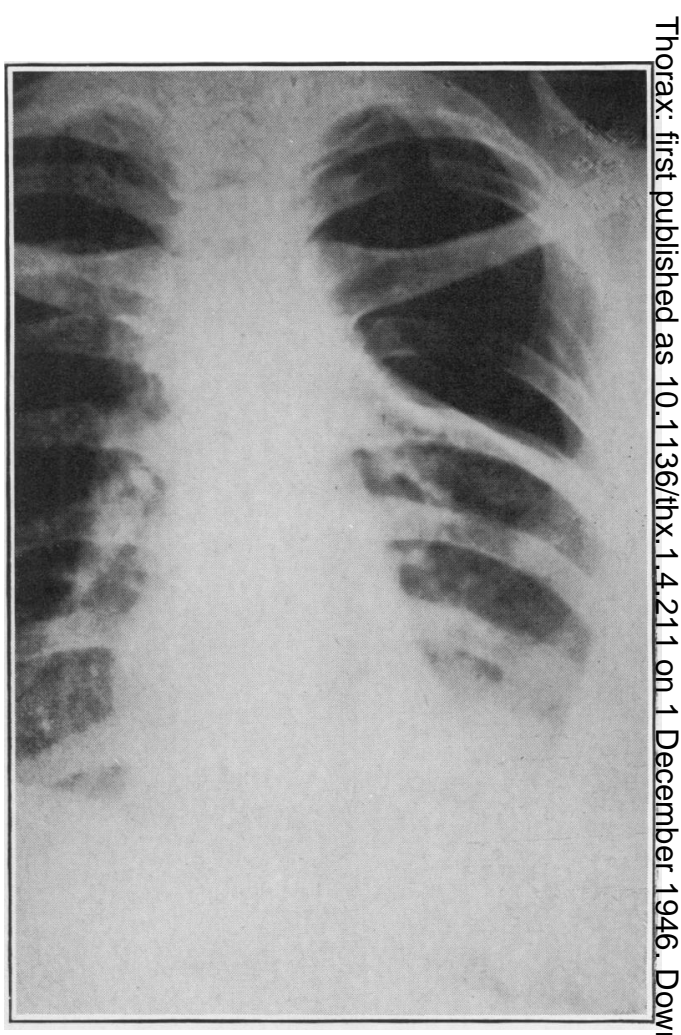

Fig. 15.- Shows a well-marked extrapleuralo space, with disappearance of the originalo cavity (Case 35).

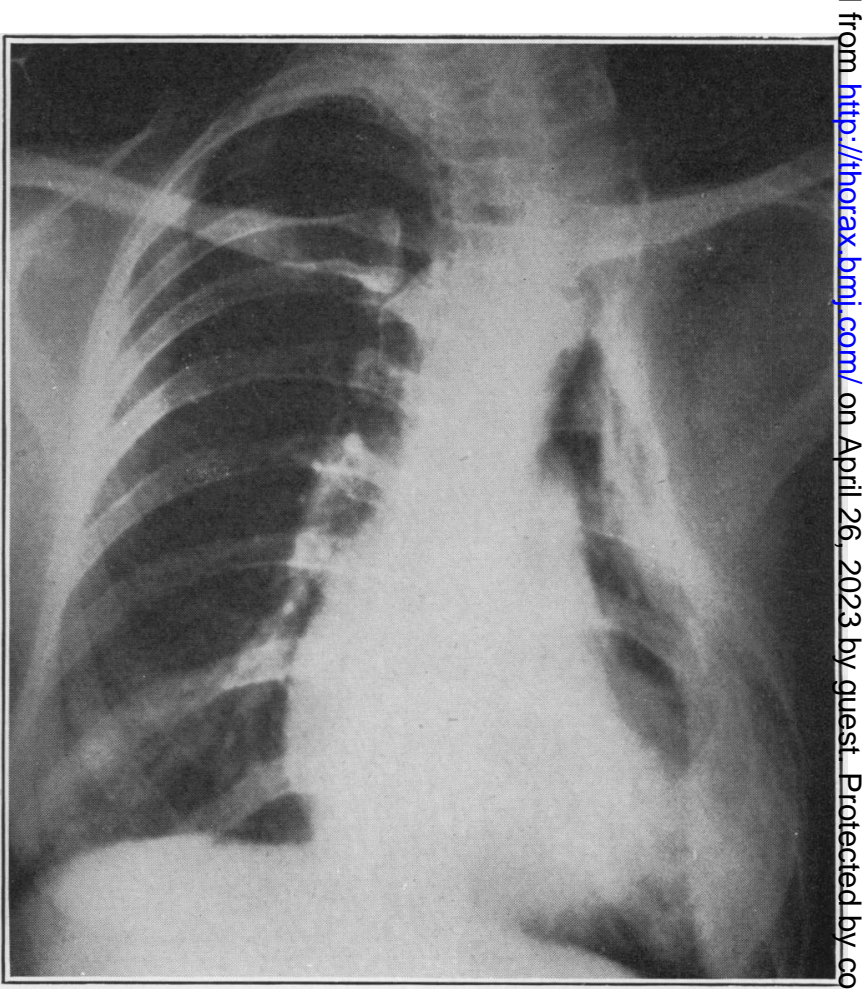

FIG. 17. -There is effective upper thoracoplasty with disappearance of the lung cavity (Case 35 ). 

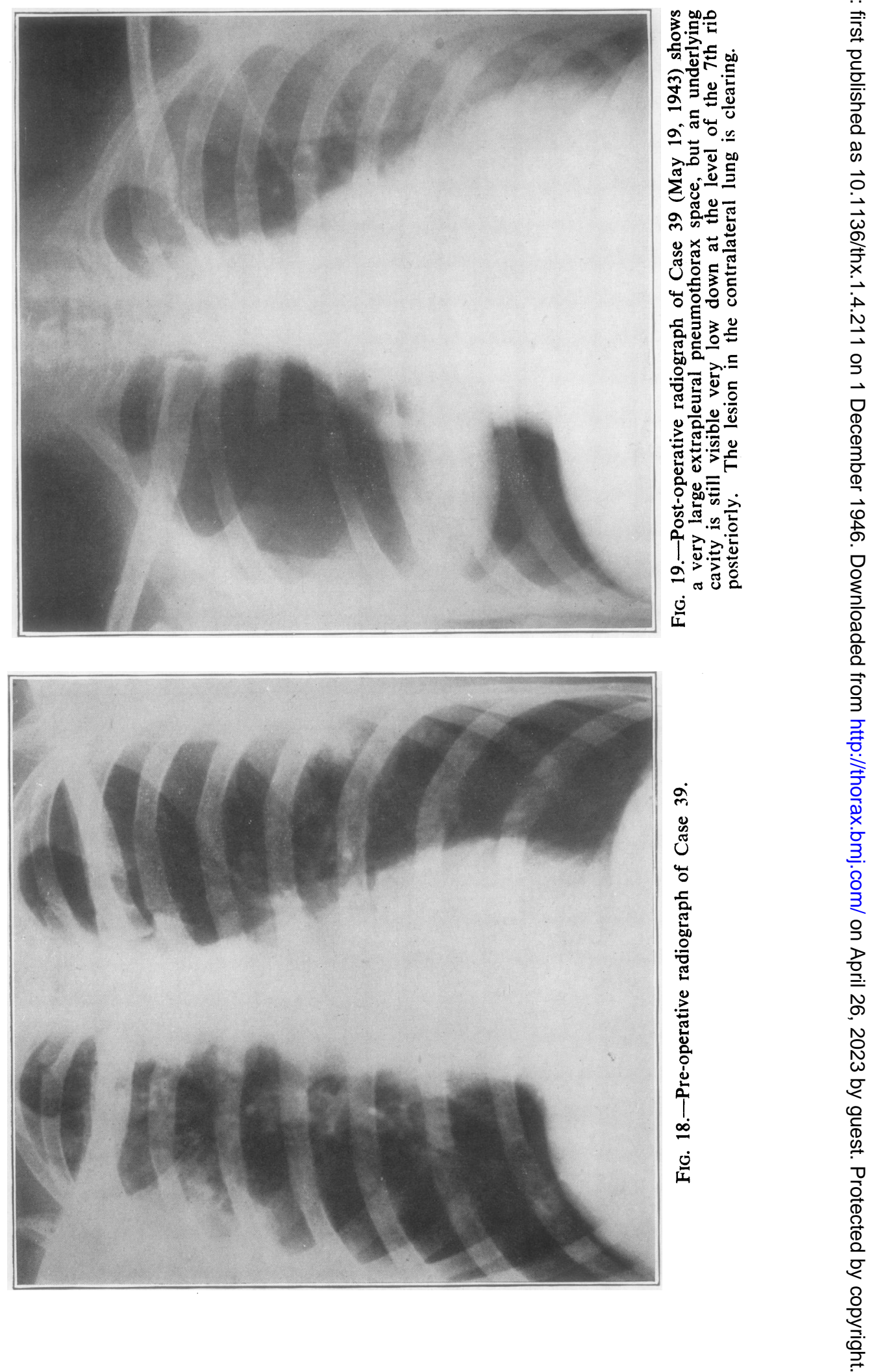

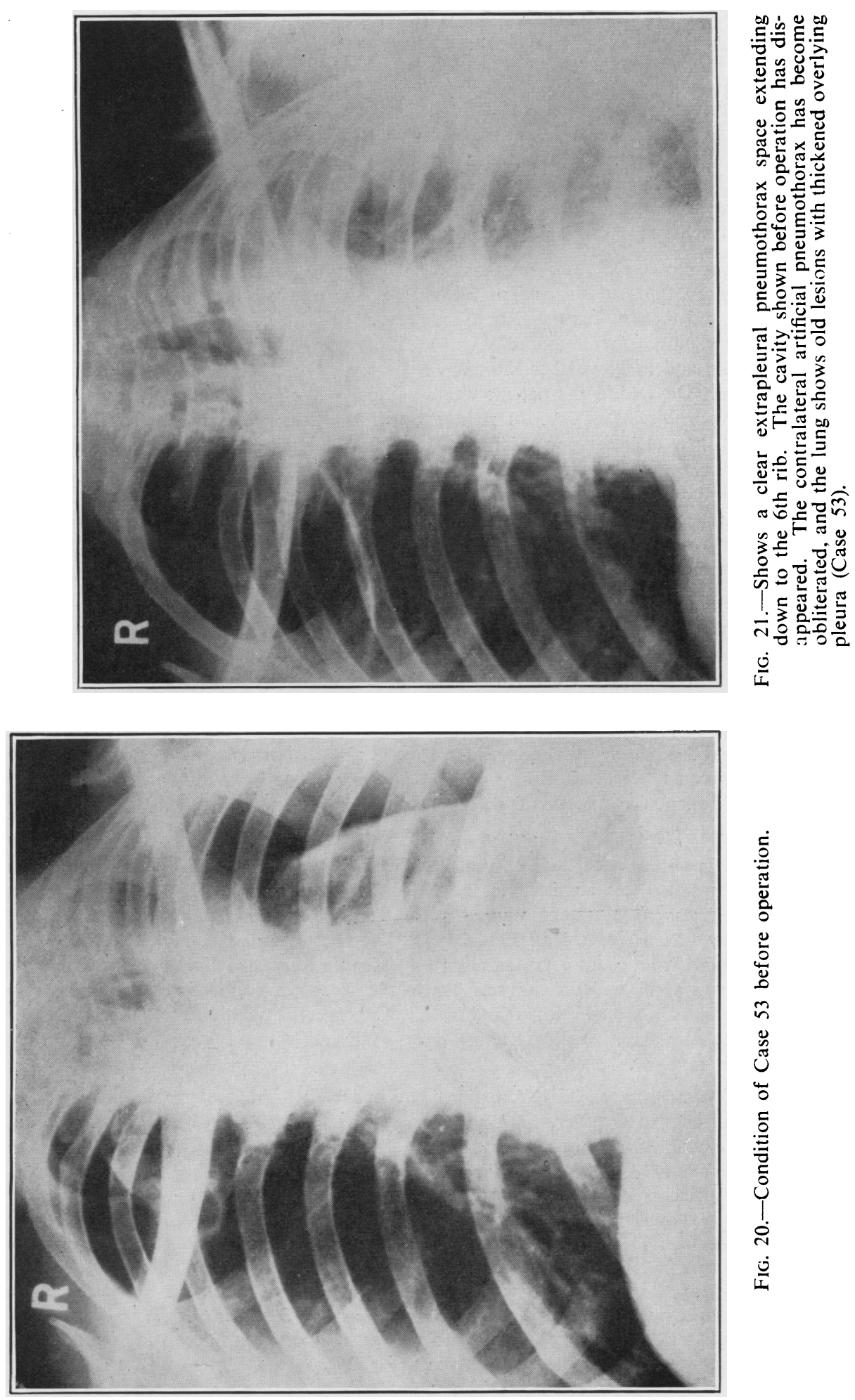
Wales Sanatorium for operation (Fig. 6). On Oct. 15, 1940, left extrapleural pneumothorax was performed. On Dec. 6 he was discharged to Southport and bed rest was ordered. On Jan. 17, 1945, a report from the tuberculosis officer was as follows: "He has kept well since. Has continued without break at his work as a senior official in the Unemployment Assistance Board. He has very little morning sputum, which is negative, and he continues his refills at intervals of a fortnight, ending in high positive pressure " (Fig. 7).

CASE 22 (woman, aged 22).-In December, 1938, this patient was diagnosed as suffering from pulmonary tuberculosis, and in May, 1939, she was admitted first to Romsley Hill Sanatorium, and then to Yardley Road Sanatorium, Birmingham. In October, 1939, right artificial pneumothorax was induced (Fig. 8). She was transferred to Southport Sanatorium in May, 1940, and in November thoracoscopy was performed. Adhesions were found to be indivisible. On Dec. 6 the patient was admitted to the North Wales Sanatorium. Her sputum was positive. On Dec. 10 right extrapleural pneumothorax was performed, and was extended into artificial pneumothorax. She was discharged to Southport, and ordered bed rest. The general condition was good, she was afebrile with no symptoms and no sputum, and the blood sedimentation rate was 54/84. In January, 1945, the following report was received from the tuberculosis officer, Southport: "She has kept very well. She does her own housework. Has little dyspnoea on exertion but no sputum. Her refills continue at intervals of three weeks. Average readings, 8.0 and $0.8: 350 \mathrm{ml}$." (Fig. 9.)

CASE 29 (man, aged 21).-After a history of dry cough with stained positive sputum, this patient was admitted to the North Wales Sanatorium on June 26, 1942 (Fig. 10). On Sept. 23 left artificial pneumothorax was induced, but this was later found to be ineffective and was discontinued on Oct. 10. On Oct. 20 left thoracoscopy revealed an extensive pleural symphysis at the apex. On Dec. 11 left extrapleural pneuomothorax was performed. Stripping was easy, but there was oozing, the parietal pleura were punctured (Fig. 11) and later there was troublesome vomiting. On Jan. 12, 1943, thoracoscopy was performed and the shelf between the artificial pneumothorax and extrapleural pneumothorax divided. On April 16 the patient was discharged with no symptoms and in good general condition. The blood sedimentation rate was $4 / 10$.

CASE 34 (woman, aged 26).-A patient who in August, 1942, had had a haemoptysis and positive sputum was admitted to the North Wales Sanatorium in January, 1943, and on Jan. 11 left artificial pneumothorax was attempted without success (Fig. 12). Left phrenicectomy was performed on Feb. 23, and left extrapleural pneumothorax on April 6 (Fig. 13). There was a small persistent effusion which on direct examination showed tuberculosis. This was confirmed on culture. The patient was considered for thoracoplasty, but the right side was not thought fit to stand it. She had repeated wash-outs with azochloramide, and was discharged on April 2 feeling very well and without symptoms. The blood sedimentation rate was $13 / 45$.

CASE 35 (woman, aged 26).-A patient who had been losing weight and suffering from colds and fainting, in October, 1942, after haemoptysis $(2 \mathrm{oz}$.) was shown by radiographic and sputum examination to be suffering from pulmonary tuberculosis (Fig. 14). On Jan. 15, 1943, she was admitted to the North Wales Sanatorium, and on Jan. 23 left artificial pneumothorax was unsuccessfully attempted. On April 13 left extrapleural pneumothorax was performed. A blood-stained effusion was aspirated and dried up. Culture was negative (Fig. 15). On June 15 right phrenicectomy was performed, and on July 21 the patient was ordered gold therapy. In November, 1943, in view of the re-opening of the cavity (Fig. 16), a left upper rib thoracoplasty was performed. A purulent discharge from the wound opened into old empyema, and Staphylococcus aureus was found in the pus on culture, but no tuberculosis. On Sept. 18, 1944, the patient was discharged in fairly good condition and without symptoms. She was fit for light work (Fig. 17). 
CASE 39 (man, aged 24).-A patient suffering from cough with slight sputum was radiographed in October, 1942, and pulmonary tuberculosis was diagnosed. On Nov. 7 he was admitted to the North Wales Sanatorium (Fig. 18). Sputum was positive on concentration, and on Nov. 14 right artificial pneumothorax was induced. On Dec. 8 right thoracoscopy was performed, but adhesions were found to be indivisible. On May 18, 1943, right extrapleural pneumothorax was performed (Fig. 19). Later, altered blood was aspirated, and $B$. coli but no tubercle bacilli were found. On Nov. 30 right phrenicectomy was performed. On Jan. 18, 1944, the patient was discharged to Talgarth Sanatorium. He was in good general condition, afebrile with no cough or sputum. Blood sedimentation rate was 5/19.

CASE 53 (man, aged 24).-A patient suffering from cough and haemoptysis had a left artificial pneumothorax induced in November, 1941. Left thoracoscopy was performed in February, 1942, and in November, 1943, he was admitted to the North Wales Sanatorium. On Nov. 25, 1943, right artificial pneumothorax was induced. Aspiration of purulent fluid later on showed tubercle bacilli on direct examination (Fig. 20). On Feb. 22, 1944, right thoracoscopy was performed, but no division of adhesions was possible. On April 11 a right extrapleural pneumothorax was performed (Fig. 21). Stripping was difficult, a tear was made in the pleura, and this was followed by slight blood-stained effusion. On June 20, 1944, the patient had a left phrenicectomy, and on Aug. 18 he was discharged to Talgarth Sanatorium in good general condition, afebrile, with a slight cough but no sputum. Faeces were positive, and the blood sedimentation rate $10 / 39$. He was able to walk $1 \frac{1}{2}$ miles a day.

\section{Discussion}

It has been argued that the ideal way to treat patients with persistent apical cavities is to perform a primary thoracoplasty with apicolysis (Semb's operation). This operation is a formidable procedure in itself ; it is shocking to the patient, and, by taking away the support of the thoracic cage, increases the risk of bronchogenic dissemination. If the patient's resistance is unduly low, tuberculous infection may cause the whole wound to break down, and the result is deplorable. Moreover, Semb's operation is dangerous if the contralateral lung is unstable, and it is in such cases that extrapleural pneumothorax finds its most satisfactory application.

Extrapleural pneumothorax is a very much less severe operation and can tide the patient over until he is sufficiently fit for thoracoplasty. In other words, extrapleural pneumothorax may be regarded as the first stage in a Semb's thoracoplasty. An extensive apicolysis having been carried out, and the lesion having been stabilized, the upper ribs may subsequently be removed with safety. The disease should preferably be limited to above the fifth rib posteriorly, but no strict adherence to this rule is insisted on. The size, character, and position of the lesion, including cavities, are immaterial. Tension cavities react better to this form of treatment than to thoracoplasty unless there is bronchial stenosis, because concentric relaxation allows reopening of the draining bronchus, and the actual positive pressure of air in the extrapleural pneumothorax space compresses the cavity. The disadvantages of using extrapleural pneumothorax in this way are, firstly, that there is one extra stage to be carried out, and secondly, that removing a regenerated rib can be difficult, with a risk of perforation into the extrapleural pneumothorax space. 
Special indications for extrapleural pneumothorax are:

1. Severe toxaemia.-In cases showing toxaemia extrapleural pneumothorax produces such an improvement that secondary thoracoplasty is made possible.

2. Relatively recent infiltrative disease, in which symphysis of the pleura prevents artificial pneumothorax, and for which other methods have failed. Approximately $20 \%$ of patients for whom artificial pneumothorax is undertaken have such extensive adhesions that no artificial pneumothorax space can be obtained.

3. Age of the patient.-Thoracoplasty under the age of 14 tends to produce severe deformity. Cleveland (1937) pointed out that the curvature began at once while the patient was in bed, and he doubted if any posture or extrinsic brace could be devised which these patients would tolerate, as they required the unhampered action of the remaining lung ; they would not submit to a jacket, whether plaster or celluloid.

Over the age of 50 , patients, especially men, do not stand thoracoplasty well, particularly if the contralateral lung is affected.

4. Control of haemorrhage.-Lesion in apex not controlled by artificial pneumothorax.

5. Large cavities situated in the centre of the apex of the lung spread themselves against the mediastinum in spite of extensive thoracoplasty and persist in the form of a cleft. If Semb's operation cannot be done, extrapleural pneumothorax should be performed, preferably as a temporary measure with possibility of thoracoplasty later.

6. Presence of active disease on the opposite side.-Bilateral extrapleural pneumothorax can be done if necessary.

7. Where the vital capacity is low.-The preservation of as much lung tissue as possible is valuable, and one is justified in carrying out the least radical procedure consistent with good results. Gaubatz (1938) has shown that, of all operative methods of collapse therapy, extrapleural pneumothorax is the most sparing, even in bilateral cases, on the vital capacity, the heart, and the circulation.

Extrapleural pneumothorax may be compared with intrapleural artificial pneumothorax. This procedure is now well established, and its complications, such as infection, are similar to those of extrapleural pneumothorax. Cold (1939) has brought forward recent statistics to show that, with an effective artificial pneumothorax, patients after three years' inactivity are to be considered normal persons as far as the risks of active tuberculosis are concerned. The same may be claimed for extrapleural pneumothorax.

The formation of an artificial dead-space has been called a surgical heresy, and this has led de Winter and Sebrechts (1932) to reintroduce muscle grafts to fill the cavity. Such a procedure entails a greater strain on the patient than a simple extrapleural pneumothorax, and the authors themselves admit that shrinkage of as much as $40 \%$ of the original muscle volume takes place.*

\footnotetext{
*In a personal communication (1946) Prof. Sebrechts tells me that he only performs this operation in a very limited group of patients. -N. R. B., Editor.
} 
The outstanding objection to plombage is that one cannot use a plombe big enough to fill the extrapleural space without risking slipping of the plombe, quite apart from the dangers of ulceration and the difficulties with effusion.

\section{TECHNIQUE}

Anaesthesia.-One hour before the operation is due to start, the patient is given a hypodermic injection of omnopon 1/3 gr. and scopolamine 1/150 gr. Immediately before operation $0.5 \mathrm{~g}$. of pentothal sodium is injected intravenously. Cyclopropane is then administered by closed circuit during the whole operation. This produces quiet, almost imperceptible respirations, the recovery rate is rapid, and there is a minimum of vomiting and other untoward effects.

Operative Technique.-The incision, although not so extensive, should be made in the line of an ordinary thoracoplasty incision and not along the line of the rib. This allows a thoracoplasty to be done should the extrapleural pneumothorax fail to strip satisfactorily, assuming the patient is suitable for the thoracoplasty.

The inner part of the 4th rib (or possibly the 3rd or 5th rib) having been removed from the costo-transverse joint outwards for about 4 in., the intercostal muscles at the upper border of the periosteum of the rib are divided. A finger is inserted between the deep surface of the $3 \mathrm{rd}$ rib and the endothoracic fascia. It may be found that so much peripleuritis is present that separation of the parietal pleura from the inner surface of the chest wall is difficult or impossible. Considerable surgical judgment is required to decide whether to proceed in the face of difficulty, at the risk of tearing the underlying lung and possibly of opening up a tuberculous cavity, or whether to abandon the operation altogether, or to go on to a thoracoplasty.

If the stripping proceeds smoothly, the apex of the lung is reached and cautious separation is carried out in all directions. Most of the dissection is done under direct vision by gauze held in forceps. A small flexible lamp is used for illumination. As the ligaments of Zuckerkandl and Sebileau, together with stiff bands and adhesions due to peripleuritis, are encountered, they must be carefully peeled down. The knife or scissors should not be used to divide such adhesions. It is essential that the stripping be extensive, because although the size of the extrapleural pocket may increase with the weight of effusion in the first few days after operation, it diminishes in the following weeks. The hilum of the lung must certainly be reached. On the left side separation should be carried down as far as the under surface of the aortic arch, and on the right as far as the azygos vein. Anteriorly the 3rd costal cartilage should be reached, and posteriorly the 7th rib or lower. The strip should be lower anteriorly to allow easy aspiration post-operatively, and there should be a clear margin from back to front laterally to avoid secondary pockets.

Spurting vessels must be dealt with by ligature: diathermy produces necrosis of tissue far greater than is visible on the surface, and is responsible for secondary haemorrhage and sepsis through devitalization of tissue. Oozing is controlled by the insertion of hot saline packs.

Closing the Wound.-When haemorrhage has been controlled, closure of the wound may be undertaken. The intercostal muscles are sutured by continuous No. 0 catgut, aided mesially by drawing the serratus posticus superior over the inner end of the wound; then the rhomboids and the trapezius are sutured in an attempt to bring about airtight closure. It is better to seal the wound during inspiration, for I have noticed that when this is done the pressure after operation is generally high, and the space is more easily entered by the refill-needle. Firm elastoplast strapping is used as a routine dressing, as this materially limits surgical emphysema, which may appear immediately after the operation, or during the early days when pressures are being adjusted. 
Maintenance of the Extrapleural Pneumothorax Space.-Immediately the patient returns to the ward, a pneumothorax needle is inserted anteriorly between the 2 nd and 3rd ribs into the air pocket and the pressures determined. If the wound has been sealed during inspiration, the pressures may be on the positive side; if during expiration, they may be negative. The aim should be to keep the pressure at atmospheric level. The average amount of air required for this purpose varies between 100 and $200 \mathrm{ml}$., but sometimes up to $300 \mathrm{ml}$. are required. If a co-existing intrapleural pneumothorax is present it is safer to obtain an early portable radiograph before giving any injection of air. The same evening a further refill is given as the radiograph or the pressures indicate.

The next day the patient is screened, or a portable radiograph is taken, and it may be necessary to remove the haemorrhagic fluid and replace with air. In the early post-operative period, pressures may increase or decrease considerably within a short time. It is inadvisable to try to establish positive pressures from the very onset in the hope of keeping the lung well collapsed, because the cellular spaces are permeable and surgical emphysema of the neck or mediastinum will be produced. On the second or third day, more fluid may accumulate and should be aspirated. The needle must be inserted from the air-pocket downwards on to the surface of the fluid. This helps to obviate puncture of the lung. I consider that puncturing the lung at this time is one of the causes of a subsequent tuberculous effusion. During these vital early days it is essential to nurse the patient in the Fowler position.

When the space has become airtight, the pressure can be increased to a mean of $+10 \mathrm{ml}$. of water. At the end of a fortnight, refills are required about every four days until the third week. After the third week, refill times can be extended to seven days, and after a month to every ten or fourteen days. Later than this, the intervals are even longer, i.e., one month, and it is permissible to increase the pressure to +30 .

The space is dry at the end of 10 or 14 days, and any small lip of effusion is best left alone as fibrin deposition materially helps to make the space airtight.

\section{Complications}

Infection of the Extrapleural Pneumothorax Space.-In this series of 54 cases, 11 developed tuberculous infection, and 4 developed infection due to other bacteria (B. coli, streptococci, pneumococci and staphylococci) in the extrapleural space.

The fate of patients who developed a tuberculous infection of the space is interesting. One died after two months, two died after four years, two are alive (four and one years respectively) but in poor condition, and six are alive and in good condition, four after four years-one of these having had a healthy baby some weeks ago, and two being recent cases. (See Table IIIA.)

Purulent fluid has been encountered in four cases; in two cases B. coli were present ; in one pneumococci and streptococci; and in one, staphylococci. None of these cases died, and all became sputum negative and able to work, although the extrapleural space later became obliterated. (See Table IIIB.)

Treatment for both tuberculosis and mixed infection has consisied of washing out the cavity through a needle, using sodium tretradecyl sulphate in azochloramide solution. I have recently inserted both sulphathiazole and penicillin into the extrapleural space at the time of operation, and no case of secondary infection has been met with since early 1945 .

Tearing of pleura in the presence of artificial pneumothorax.-If this is done inadvertently, no harm usually results as long as the accident is recognized. No attempt should be made to suture the aperture, but it should be widely extended out to the chest-wall and then circumferentially so as to open up the extrapleural into the intrapleural space, and so convert them into one large space. This was done with great success in Case 22. The post-operative radiograph shows the result after four years, the appearance being as though 
there were one large extrapleural space. The large pulmonary cavity which was visible in the previous radiographs has disappeared.

In Case 4, auricular fibrillation occurred and the operation was abandoned. A month later a thoracoscope was introduced and the shelf separating the extrapleural from the intrapleural space was divided.

If the tear is not recognized, or not completely opened up, it may be impossible to keep up the extrapleural space because the air leaks into the pleural cavity. On the other hand, the tear may seal itself leaving a well-marked extrapleural pneumothorax with an intrapleural pneumothorax below.

Two other cases are worth noting in this connexion. Although no tear was made into the pleural space, a shelf remained separating the extrapleural from the artificial pneumothorax. In one a thoracoscope was introduced a month later, and it was possible to divide the shelf completely by intrathoracic cauterization, with excellent result. A similar attempt was made in another patient, but it failed owing to vascularity of the shelf. Such a case should be reviewed later on with a view to thoracoplasty.

Haemorrhage.-One case had a post-operative haemorrhage which required a blood transfusion. The man had had a haemoptysis before the operation, for the control of which a bilateral artificial pneumothorax had been done. At operation the pleura was difficult to strip and was inadvertently punctured, and later a tuberculous effusion developed in the space and his refills had to be abandoned. When discharged from hospital he still had positive sputum.

I have recently observed a special point of interest with regard to clotting of blood in the extrapleural space. It is sometimes found that the extrapleural pneumothorax space is completely opaque with a crescentic lower margin, and on attempting to aspirate the space, no fluid is withdrawn by the needle. This was thought to be due to rapid expansion of the apex in spite of careful refills and post-operative aspirations. Previously such a condition may have accounted for obliteration of the extrapleural space in some of my cases. I now explore such cases surgically by making an adequate incision, and, after evacuating the blood clot digitally, find a smooth space which can be completely dried out, leaving a clean lining. The exploratory incision is then sutured and the space becomes suitable for further refills.

Shock.-Shock has not been encountered except in the one instance, described above The patient developed Cheyne-Stokes breathing during the operation, but he recovered after treatment.

The opening of a tuberculous cavity in the underlying lung has not happened in any of my cases, although a cavity of considerable magnitude has often been present in the apex. To avoid this accident it is essential to keep all pressure of the separating finger or instrument directed towards the chest wall and away from the underlying lung.

Subcutaneous Emphysema.-This nearly always occurs, and varies from slight crackling around the wound to extensive swelling passing upwards to the neck, or downwards to the buttocks and scrotum. This adds considerably to the discomfort of the patient, but is not serious. The steps taken to avoid it are, (1) by anaesthesia, to keep the patient quiet and not coughing, (2) careful suture of the wound, and (3) avoidance of too high a pressure from the refills immediately after operation.

Pyrexia.-The temperature frequently rises to $100^{\circ}-101^{\circ} \mathrm{F}$. for 2 or 3 days, and then drops by lysis within a week unless other complications arise.

Post-operative pain is not severe after this operation because the incision is small, without tension or pressure on nerves, and the support of the chest wall has not been interfered with. 
Displacement of the mediastinum is minimal. It is this, combined with the absence of paradoxical respiratory movement, that makes bronchogenic spread rare and gives a chance of early control of disease.

\section{CoNCLUSIONS}

Fifty-four cases have been operated on between 1938 and 1944. The special questions I have set out to answer are:

1. What is the fate of the extrapleural space after a lapse of four years?

2. Does the space remain, or does it become obliterated, and if it becomes obliterated does this invalidate the operation?

3. What number of cases become infected by tubercle bacilli or other organisms, and how does this affect the general result?

4. What is the condition of the patient on leaving the sanatorium after operation, as compared with his previous condition?

5. What part of the mortality is due to the operation itself, and what part due to spread of the disease?

6. Is the patient cured, as far as cure of tuberculosis is possible, and as evidenced by conversion of his sputum from positive to negative and by his capacity for work, or will some further measure such as thoracoplasty be required later?

A consideration of the tables below will give the answers.

TABLE II

\begin{tabular}{|c|c|c|c|c|c|}
\hline \multicolumn{2}{|c|}{$\begin{array}{l}\text { Fate of Extrapleural } \\
\text { Pneumothorax Space } \\
\text { Judged on the "old " cases } \\
\text { which have been observed over } \\
\text { four years. (17 cases) }\end{array}$} & \multicolumn{2}{|c|}{$\begin{array}{c}\text { A } \\
\text { Fate of cases with Persisting } \\
\text { Extrapleural Pneumothorax } \\
\text { Space. (6 cases) }\end{array}$} & \multicolumn{2}{|c|}{$\begin{array}{c}\text { B } \\
\text { Fate of cases with Obliterated } \\
\text { Extrapleural } \\
\text { Pneumothorax } \\
\text { (11 cases) }\end{array}$} \\
\hline $\begin{array}{l}\text { A. Persistence of space } \\
\text { B. Obliteration of space }\end{array}$ & $\begin{array}{r}6 \\
11\end{array}$ & $\begin{array}{l}\text { Condition good, fit for } \\
\text { work, negative sputum } \\
\text { Fair condition, not work- } \\
\text { ing, positive sputum }\end{array}$ & $\begin{array}{c}5 \\
1 *\end{array}$ & $\begin{array}{l}\text { Condition good, fit for } \\
\text { work, negative sputum } \\
\text { No written report from } \\
\text { tuberculosis officer, but } \\
\text { satisfactory film taken } \\
\text { after } 5 \text { years }\end{array}$ & 10 \\
\hline Total & 17 & Total & 6 & Total & 11 \\
\hline
\end{tabular}

* (Has been advised thoracoplasty but refused)

Roughly two-thirds of cases traced over four years obliterate their extrapleural space. Examination of a series of films of cases after operation shows an imperceptible obliteration over a series of months. The rate of obliteration varies and no doubt depends to some extent upon the judgment of the tuberculosis 
officer responsible for after-care, but the results are good, and only one required thoracoplasty. It might be expected that those with persisting spaces should do well clinically, and indeed, out of the six cases presented, only one has failed to benefit.

In my earlier cases I did not make such an extensive stripping down of the apex, particularly on the mediastinal side, as in the later cases. This was due to a fear, not subsequently justified, that intractable haemorrhage might be caused by such widespread stripping. Hence the results of the later cases may be expected to be better.

TABLE III

\begin{tabular}{|c|c|c|c|c|c|}
\hline \multicolumn{2}{|c|}{$\begin{array}{l}\text { Total Number of Infections } \\
\text { of the Extrapleural Space in } \\
\text { the Whole Series } \\
\text { ( } 54 \text { cases) }\end{array}$} & \multicolumn{2}{|c|}{$\begin{array}{c}\text { A. Fate of Cases with Infec- } \\
\text { tion of Extrapleural Pneumo- } \\
\text { thorax Space with Tubercle } \\
\text { Bacilli }\end{array}$} & \multicolumn{2}{|c|}{$\begin{array}{l}\text { B. Infection of Extrapleural } \\
\text { Pneumothorax Space with } \\
\text { other than Tubercle Bacilli }\end{array}$} \\
\hline $\begin{array}{l}\text { A. With tubercle } \\
\text { bacilli . . } \\
\text { B. With other or- } \\
\text { ganisms }\end{array}$ & $\begin{array}{r}11 \\
4\end{array}$ & $\begin{array}{l}\text { Died after two } \\
\text { months . } \\
\text { Died after four } \\
\text { years . } \\
\text { Alive, but poor con- } \\
\text { dition } . . \\
\text { Alive and in good } \\
\text { condition }\end{array}$ & $\begin{array}{l}1 \\
2 \\
2 \\
6^{*}\end{array}$ & $\begin{array}{lr}\text { B. coli } & \\
\text { Pneumococci } & \text { and } \\
\text { streptococci } & . . \\
\text { Staphylococci } & \text {.. }\end{array}$ & $\begin{array}{l}2 \\
1 \\
1\end{array}$ \\
\hline Total & $\begin{array}{c}15 \\
(27 \cdot 7 \%)\end{array}$ & Total & $\begin{array}{c}11 \\
(20 \cdot 4 \%)\end{array}$ & Total & $\begin{array}{c}4 \\
(11 \%)\end{array}$ \\
\hline
\end{tabular}

* One of these has given birth to a healthy baby some weeks ago.

None of these cases died. All were much improved and were sputum negative on leaving the sanatorium. This is not a large number of extraneous infections, considering that the resistance of the patient is low and an extensive cellular space has been opened up. Although the incidence of tuberculous infection is fairly high $(20.4 \%)$, the results are not as bad as might be expected. Out of eleven cases, eight are alive and six of these in good condition.

I have noted that tuberculous empyema in the space is not associated with extensive stripping, but with attempting to perform an extrapleural pneumothorax where the apex is very adherent. Added to this it is probable that in the earlier cases the refill needle was occasionally passed through lung tissue and so infected the space. In the latter cases the needle has been passed downwards from the upper part of the space on to the surface of the fluid, and damage to lung tissue was avoided.

Recently two extrapleural pneumothorax spaces were opened into at the time of an early thoracoplasty which followed. Each showed sloughing of the cavity wall. This is probably the most potent cause of tuberculous extrapleural empyema - the wall of the extrapleural space suffering from ischaemia after the separation from the chest wall. 
TABLE IV

Immediate and Remote Mortality in the Total 54 cases

A. Directly due to operation

B. Due to the spread of the disease soon after operation ..

C. Due to the remote spread of the disease (i.e., after 4 years)

Total $(14 \cdot 8 \%)$

A.-Case 52 died one month after operation from a pulmonary embolus following thrombosis of the innominate vein. Diathermy was used during the operation to arrest haemorrhage, and it appears that the diathermy injured the wall of the vein.

B. - Case 4 had a shelf separating the extra- from the intrapleural space which was subsequently divided. Five radiographs of her progress are shown, and although the final one looks satisfactory she did not survive for more than a year, but died of toxaemia and exhaustion. Case 7 had bilateral cavities. Because of insufficient stripping down of the apex, the extrapleural space was not well maintained. A spread took place to the contralateral side with increased cavitation and she died in just over a year. Case 23 had a satisfactory extrapleural pneumothorax which brought about closure of a very large cavity in the upper lobe, but disease in the opposite lung became reactivated, and she died from this after fifteen months. Case 31 developed a tuberculous empyema in his extrapleural space and a spread to the contralateral lung. He died two months later. A. and B. together may be taken to represent the mortality from the operation (9\%).

C.- Case 9 had a good extrapleural space, but developed a tuberculous empyema in it, and the rest of the lung below developed a tuberculous spread. She died after five years. Case 16 had an extensive extrapleural space, but the cavity in the apex was merely displaced downwards. Three months later she was sufficiently well to undergo thoracoplasty. This was advised, but she refused

TABLE V

\begin{tabular}{|c|c|c|c|}
\hline \multicolumn{2}{|l|}{ Sputum Conversion } & \multicolumn{2}{|l|}{ Immediate Results } \\
\hline $\begin{array}{l}\text { Cases leaving sanatorium with sputum } \\
\text { conversion } . . \\
\text { Cases with negative or no sputum on } \\
\text { admission and negative on discharge } \\
\text { Cases leaving sanatorium with positive } \\
\text { sputum . } \\
\text { Cases dying in sanatorium or soon after } \\
\text { discharge } \quad . .\end{array}$ & $\begin{array}{r}37 \\
10 \\
3 \\
4\end{array}$ & $\begin{array}{l}\text { Discharged from sanatorium in good } \\
\text { condition } \\
\text { Discharged from sanatorium in fair } \\
\text { condition } \\
\text { Discharged from sanatorium in poor } \\
\text { condition } \\
\text { Deaths in the whole series (including } \\
\text { remote deaths after } 4 \text { years) } \ldots\end{array}$ & $\begin{array}{r}30 \\
9 \\
7 \\
8\end{array}$ \\
\hline Total .. & 54 & Total & 54 \\
\hline
\end{tabular}


and died within four years. Case 17 had a satisfactory extrapleural space and the large cavity in her apex became obliterated. She lived for four years and no details of the cause of her death can be obtained.

\section{SUMMARY}

Extrapleural pneumothorax is not a substitute for other procedures, but is complementary to them. These observations are intended to show the place that extrapleural pneumothorax is earning in thoracic surgery. It has special indications of its own. Its chief object is to relax the tension on pulmonary cavities and allow healing by the natural processes of repair. Thoracoplasty with apical pneumonolysis (Semb's operation) is the operation to be aimed at, but there are contra-indications to this procedure. Extrapleural pneumothorax fills sometimes a temporary, sometimes a permanent, gap in collapse therapy. My own results show that extrapleural pneumothorax can not only be a life-saving measure to tide the patient over and make him safe for a thoracoplasty, but that, as a measure in itself-whether the space is maintained indefinitely or whether it becomes obliterated-it is consistent with good general condition, working capacity, and freedom from cough and sputum, even after a lapse of four years. Further experience is convincing me that extrapleural pneumothorax, as a preliminary to thoracoplasty, avoids the risk of bronchogenic dissemination (due to loss of the support of the thoracic cage), the extrapleural-cutaneous fistulas experienced in Semb's thoracoplasty, and shock; it thus tides the patient over, controls his disease, and makes him safe for more drastic attempts to cure him.

My special thanks are due to Dr. F. S. Hawkins, Superintendent of the North Wales Sanatorium, and to Dr. G. O. Thomas, Deputy Superintendent, for their most generous help in the assessment of cases and the collection of case-sheets and radiographs, and for their untiring work in the after-care of the patients. It is a pleasure to acknowledge the help I have received from other colleagues, Fellows of the Association of Thoracic Surgeons, for the instructive hours they have allowed me to spend in their clinics and operating theatres, sharing their views and experiences. I do not forget the courtesy of those surgeons of America and of the Continent, particularly in Germany and Switzerland, whose clinics I have so frequently visited in more spacious days.

\section{REFERENCES}

Alarçon, D. G. (1943). Dis. Chest, 9, 137.

Alexander, J. (1925). The Surgery of Pulmonary Tuberculosis. Phila., Lea.

Ar (1937). The Collapse Therapy of Pulmonary Tuberculosis, Springfield, Ill., Thomas. Archibald, E. W. (1921). Amer. Rev. Tuberc., 4, 828.

Baer, G. (1913). Münch. med. Wschr., 60, 1587 .

(1921). Ibid., 68, 1582 .

Barrett, N. R. (1946). Personal communication.

Belsey, R. (1938). J. Thorac. Surg., 7, 575.

Bérard, L. (1932). Arch. méd.-chir. de l'app. respir., 7, 511.

Bernou, A., and Fruchaud, H. (1932). Ibid., 7, 559.

Bourgeois, (1939). Chirurgie de la tuberculose pulmonaire, p. 474. Paris. Doin.

Bourgeois, P., and Lebel, M. (1938). Presse méd., 46, 818.

Brock, R. C.' (1938). Brit. J. Tuberc., 32, 173.

Brunner, A. (1938). Schweiz. med. Wschr., 68, 729. 
Carson, J. (1820). Philos. Trans., 110, 29.

Cleveland, M. (1937). J. Thorac. Surg., 6, 595.

Cold, S. (1939). Tubercle, $20,301$.

Coope, R. (1944). Diseases of the Chest. Edinburgh, Livingstone.

Coryllos, P. N. (1938). Quart. Bull. Sea View Hosp., 3, 149. (1938). Ibid., 3, 264.

Davies, H. M. (1933). Pulmonary Tuberculosis: Medical and Surgical Treatment, p 411. London, Cassell.

- (1924). Brit. med. J., 2, 1145.

(1944). Nat. Ass. Prev. Tuberc. Bull., Oct., 1944, p. 6.

Dolley, F. S., Jones, J. C., and Skillen, J. (1940). Amer. Rev. Tuberc., 41, 403.

Edwards, A. Tudor (1944). Personal communication.

Felix, W., and Mindus, W. (1931). Dtsch. Z. Chir., 233, 1.

Gaubatz, E. (1938). Beitr. klin. Tuberk., 91, 201.

Geary, P. (1942). Amer. Rev. Tuberc., 46, 646.

Graf, W. (1936). Dtsch. med. Wschr., 62, 671. (1937). Ibid., 63, 4. (1938). Therap. Gegenw., $2,4$.

Hautefeuille, E., and Dreyfus-le-Foyer (1937). Presse méd., 45, 859.

Heaton, T. G. (1941). Artificial Pneumothorax in Pulmonary Tuberculosis. Toronto, Macmillan

Lauwers, M. (1929). J. Chir., Paris, 33, 483.

Lilienthal, H. (1927). Ann. Surg., 86, 182.

Matson, R. C. (1942). Amer. Rev. Tuberc., 45, 714.

Maurer, A., Hautefeuille, E., and Dreyfus-le-Foyer (1937). Mém. Acad. Chir., 63, 823.

Maurer, A., and de Savitsch, E. (1938). Lancet, 2, 1468.

Mayer, A. (1913). Dtsch. med. Wschr., 39, 2347.

Monod, O. (1938). J. Thorac. Surg., 8, 150.

Nissen, R. (1931). Surg. Gynec. Obstet., 52, 732.

- (1931). Therap. Gegenw., 72, 497. (1933). Med. Klinik., 29, 767.

(1937). Schweiz. med. Wschr., 67, 334

(1939). Brit. med. J., 1, 100.

Overholt, R. H., and Tubbs, O. S. (1938). J. Thorac. Surg., 7, 591.

Pearson, S. V. (1922). Lancet, 2, 1273.

Proust, R., Maurer, A., and Rolland, J. (1932). J. Chir., Paris, 39, 173.

Rehn, E. (1937). Arch. klin. Chir., 189, 553.

Rhodes, B. (1937). Lancet, 2, 377.

Rivière, C. (1927). The Pneumothorax and Surgical Treatment of Pulmonary Tuberculosis, 2nd. ed., Oxford Univ. Press.

Roberts, J. E. H. (1938). Brit. J. Tuberc., 32, 68. (1944) Personal communication.

Róth, N. (1930). Beitr. klin. Tuberk., 74, 602.

Russo, J. G. (1943). J. Thorac. Surg., 12, 316.

Sattler, A. (1933). Mitt. Grenzgeb. Med. Chir., 43, 189.

Sauerbruch, F. (1914). Beitr. klin. Chir., 90, 247.

Schlange (1907). Verh. dtsch. Ges. Chir., 36, 80.

Schmidt, W. (1936). Beitr. klin. Tuberk., 88, 689.

(1937). Rev. de la Tuberc., 3, 1122.

(1938). Beitr. klin. Tuberk., 91, 121.

Sebestyén, J. (1933). Rev. de la Tuberc., 1, 135.

Sebrechts, T. (1929). Presse méd., 37, 1334.

Sellors, T. H. (1938). Brit. J. Tuberc., 32, 182.

Semb C. (1937) Brit. med. J., 2, 650.

Stöcklin, H. (1921). Z. Tuberk., 35, 241.

Thomas, C. Price (1942). Brit. J. Tuberc., 36, 4.

Torek, F. (1914). Dtsch. Z. Chir., 131, 132.

Tuffier, T. (1891). Sem. méd., 11, 202.

- (1895). Gaz. Hôp., 68, 1320. (1923). Etat actuel de la chirurgie intrathoracic, Paris, 90, 163.

Walzel, P. (1930). Wien. med. Wschr., 80, 1251.

Winter, L. de, and Goffaerts (1927). J. Chir. (Brux.), 36, 145. and Sebrechts, J. (1932). Arch. méd.-chir. de l'app. respir., 7, 377. (1939). Tubercle, $20,328$.

Winternitz, A. (1932). Dtsch. Z. Chir., 235, 752. 